\title{
Evaluating the perception of the Decision Quality in Web-based Group Decision Support Systems: A Theory of Satisfaction
}

\author{
João Carneiro ${ }^{1,3}$, Ricardo Santos ${ }^{2}$, Goreti Marreiros ${ }^{1}$, and Paulo Novais ${ }^{3}$ \\ ${ }^{1}$ GECAD, Institute of Engineering, Polytechnic of Porto, Porto, Portugal \\ $\{$ jomrc, mgt $\}$ @isep. ipp.pt \\ ${ }^{2}$ CIICESI, School of Technology and Management of Felgueiras, Polytechnic of Porto, Fel- \\ gueiras, Portugal \\ rjs@estgf.ipp.pt \\ ${ }^{3}$ ALGORITMI Centre, University of Minho, Guimarães, Portugal \\ pjon@di. uminho.pt
}

\begin{abstract}
The future and success of organizations depend greatly on the quality of every decision made. It is known that most of the decisions in organizations are made in group. With the purpose to support the decision-makers anytime and anywhere, Web-based Group Decision Support Systems have been studied. The amount of Web-based Group Decision Support Systems incorporating automatic negotiation mechanisms such as argumentation is increasing nowadays. Usually, these systems/models are evaluated through mathematical proofs, number of rounds or seconds to propose (reach) a solution. However, those techniques do not say much in terms of decision quality. Here, we propose a model to predict the decision-makers' satisfaction (perception of the decision quality), specially designed to deal with multi-criteria problems. Our model considers aspects such as: alternatives comparison, style of behaviour, emotions, mood and expectations. The proposed formulation matches the assumptions previously defined in the literature.
\end{abstract}

Keywords: Group Decision Support Systems, Decision Satisfaction, Decision Quality, Outcomes, Affective Computing

\section{Introduction}

It is known that many of the decisions in organizations are made in group [1]. Group Decision Support Systems (GDSS) have been widely studied throughout the last decades $[2,3]$ to support this type of decisions. However, in the last ten/twenty years, we have seen a remarkable change in the context where the decision-making process happens, especially in large organizations [4]. With the appearance of global markets, the growth of multinational organizations and a global vision of the planet, we easily find decision-makers (chief executive officers, managers and other members of global vir- 
tual teams) spread around the world, in countries with different time zones [5]. However, to support the group decision-making process in this context is especially complex, due to the decision-makers being geographically dispersed. To provide an answer and operate correctly in this type of scenarios, the traditional GDSS have evolved to what we identify today as Web-based GDSS [6,7]. The idea behind the Web-based GDSS is to support the decision-making process "anytime" and "anywhere" [4]. The automatic negotiation mechanisms can be used (in Web-based GDSS) to help overcome the lack of interaction caused in the context described before [8]. Usually, these systems/models are evaluated through mathematical proofs, number of rounds or seconds to propose (reach) a solution [9]. However, those techniques do not say much in terms of decision quality.

In fact, the decision quality is impossible to measure in the end of a group decisionmaking process. What is possible to measure, or what can be valuable to know in the end of a group decision-making process is the perception of the decision-quality of each of the decision-makers (or their satisfaction) [10]. Satisfaction is therefore a strong indicator, not only of the results, but also of the whole decision process [11]. When someone is questioned about the quality of a decision, the answer does not reflect only the assessment of outcomes, but also, even unconsciously; it includes the evaluation process necessary to reach the decision [11]. Satisfaction as a metric has been applied in the literature to many different issues: life satisfaction [12], job satisfaction [13], etc. Satisfaction has also been applied in the GDSS topic. However, the existent proposals are not concerned with the perception of the decision quality but are concerned with decision-maker's satisfaction regarding the GDSS performance, usability, etc [14-16].

In this work, we study satisfaction as a metric to understand the decision-maker's perception of the decision quality. Our proposal is defined based in the assumptions and premises previously published in [10], which contemplate different approaches from researchers of a wide range of areas in this thematic (computer sciences, psychology, economy, etc.). It intends to allow automatic assessment of the participants' satisfaction in a meeting supported by a Web-based GDSS. To evaluate decision-maker's satisfaction, we consider the alternatives comparison, style of behaviour, emotions, mood and expectations.

The rest of the paper is organized as follows: in the next (Section 2) section our satisfaction model is presented and in Section 3 some conclusions are taken, along with the work to be done hereafter.

\section{Methods}

As we have seen in [10], when a decision-maker is questioned about the quality of a decision, the answer does not reflect only the assessment of the outcomes, but also, even unconsciously; it includes the evaluation process necessary to reach the decision. To understand how suitable a decision is, it is necessary to understand and analyse the means to reach that decision [17]. Thus, one should give prominence to the process, when drawing conclusions about the results. Besides, the researchers agree that there is a great variety of factors responsible for affecting the satisfaction of a decision-making 
element with the decision made in a meeting: emotional variables (affective components) [18], the process [19], the outcomes [11], the factors that affect the situation [20] and expectations [21]. Our proposal (follows the assumptions and premises proposed in [10]) deals with these factors making use of the typical data configured by the decision-makers in the Web-GDSS (in disperse meetings [22]).

\section{$2.1 \quad$ Outcomes}

The alternative chosen by the group has impact in the decision-maker's satisfaction. This is an inescapable fact, since achieving the outcomes is the reason why the decisionmaking process happens. The satisfaction or the perception of the decision quality is related to the outcomes [10]. However, to understand the outcomes impact it is necessary to see the big picture. Higgins [11] says that "psychologically, then, a decision is perceived as good when its expected value or utility of outcomes is judged to be more beneficial than the alternatives". Thus, whereas the preferred alternative is the best in the decision-maker's perspective, the distance between the preferred alternative and the chosen one means a loss of the decision-maker's satisfaction. The loss of satisfaction comprises the difference in the assessment made by the decision-maker for each of the alternatives, as well as what the participant did not achieve with the final decision. In this work, we consider the participant's assessment of each alternative varying in a $[0$; 1] range, where 0 means "I do not like at all" and 1 means "I like very much" (see our proposal of a practical implementation based on this in [23]). To understand the satisfaction considering alternatives comparison, we suggest the following formulas:

$$
\begin{gathered}
D_{\text {Lost }}=\text { Alt }_{F}-\text { Alt }_{P} \\
A_{\text {Conversion }}=2 A l t_{F}-1 \\
D_{\text {Outcomes }}=\left(1-\left|A_{\text {Conversion }}\right|\right) * D_{\text {Lost }}+A_{\text {Conversion }}
\end{gathered}
$$

Where:

- $D_{\text {Lost }}$ is the loss of decision maker's satisfaction based in the difference between the assessments made for the alternative chosen by the group $\left(A l t_{F}\right)$ and for his preferred alternative $\left(A l t_{P}\right)$. The loss is zero when the chosen alternative is the same as his preferred alternative;

- $A l t_{F}$ is the assessment made by the participant for the final alternative, alternative chosen by the group;

- $A l t_{P}$ is the assessment made by the participant for his preferred alternative;

- $A_{\text {Conversion }}$ is the conversion of the assessment made by the participant into our scale of dissatisfaction/satisfaction;

- Doutcomes is the participant's satisfaction concerning the outcomes. Intends to evaluate the satisfaction based in the assessment made by the participant to the alternatives, including the loss of satisfaction in the case where his preferred alternative is not chosen by the group. 
We assume the $D_{\text {Outcomes }}$ is the purely analytical evaluation of the decision-maker's satisfaction. All other points (presented below) have impact in $D_{\text {Outcomes }}$. The other points will depend on the context.

\subsection{Expectations}

Consciously or not, people create expectations on (almost) everything [21]. The relationship between expectations and the satisfaction is clear. Considering what we have stated before and our previous work [10], it is easy to understand the following rules:

If Participant achieve goals $=$ True

Then expectations impact $=$ Positive or Neutral

If Participant achieve goals $=$ False

Then expectations impact $=$ Negative or Neutral

In this work, we consider the Web-based Group Decision Support System as the only existent mechanism for the decision-makers communicate. Thus, we consider relevant to know the decision-makers' expectations regarding the chances in attaining their objectives.

- Probability of the participant's preferred alternative to be chosen: Understanding the expectations regarding the probability of the participant's preferred alternative to be chosen. "How likely you think your preferred alternative will be chosen?".

In a real scenario, decision-makers are creating expectations all the time: "Is he going to accept my request?", "Will he help me supporting my idea?", etc. However, when automated negotiation techniques are used, the decision-makers only create expectations about issues that they can expect something and which they interact. That is why we only consider the expectations regarding the achievement of results (at this step). The expectations can influence satisfaction in three different ways:

- Positive impact: When the results exceed the expectations;

- Negative impact: When the expectations are not achieved;

- Without impact: When the expectations are achieved.

The expectation value will be within the range $[0 ; 1]$. To evaluate expectation in this context, approaches as the ones proposed in [23] can be used. The calculus of satisfaction including expectations is divided in 2 different conditions. Firstly, we address the situation where expectations are matched. This means, the expectations have a positive impact in satisfaction.

Positive Impact. This type of impact occurs when the chosen alternative is the one preferred by the participant. In this case, the impact of the expectation will be positive or neutral (in case the expectation is 1). The following formula is used to calculate the positive impact: 


$$
P_{\text {Impact }}=(1-E) * A l t_{P}
$$

Where:

- $E$ is the participant's expectation regarding the possibility of his preferred alternative being chosen by the group.

For a better understanding of the proposed formula, let us consider the scenarios where the impact should have the maximum and minimum values (extreme cases):

- The positive impact should be 1 (maximum impact) when the participant's expectation regarding the preferred alternative being chosen by the group is 0 and the value of alternative assessment is 1 ;

- The positive impact should be 0 (no impact) when the participant's expectation regarding the preferred alternative being chosen by the group is 1 . This means that the decision-maker is taking it for granted. The maximum expectation on a positive situation does not bring any increased satisfaction as a form as impact.

We can include now the expectations in the satisfaction calculation. $D_{\text {outcomes }}$ can be recalculated using the following formula:

$$
D_{\text {outcomes }}=D_{\text {outcomes }}+\left(1-\left|D_{\text {outcomes }}\right|\right) * P_{\text {Impact }}
$$

The most important point of this formulation is the possibility to recalculate the $D_{\text {Outcomes }}$ satisfaction using the impact in a form of a variable.

In our proposal, we first understand which impact the expectation has (according to the different situations) and use the correct impact next (calculated according to the context). The use of $(1-E)$ in our formula intends to reflect the difference between the maximum expectation (which would be 1) and the participant's expectation.

Negative Impact. This type of impact occurs when the chosen alternative is not the one preferred by the participant. In this case the impact of the expectation will be negative or neutral (in case the expectation is 0 ). The following formula is used to calculate the negative impact:

$$
N_{\text {Impact }}=\left(\text { Alt }_{P}-A l t_{F}\right) * E
$$

In the case of a negative impact, we propose a different formula because in this situation the impact represents an expectation that has not been met, symbolizing a loss. Moreover, in this situation, to truly understand the expectation impact, we need to analyse the relation between this loss and the difference between the assessments of his preferred alternative and the one chosen by the group. As we have done before, let us consider the scenarios where the impact should have the maximum and minimum values (extreme cases):

- The negative impact should be 1 (total impact) when the participant's expectation regarding the preferred alternative being chosen by the group is 1 , the assessment of 
the alternative chosen by the group is 0 and the assessment of his preferred alternative is 1 ;

- The negative impact should be 0 (no impact) when the expectation is 0 .

We can include now the expectations in the satisfaction calculation. $D_{\text {Outcomes }}$ can be recalculated using the following formula:

$$
D_{\text {Outcomes }}=D_{\text {Outcomes }}+\left(\left(1-D_{\text {Outcomes }}\right) *(-1)\right) * N_{\text {Impact }}
$$

\subsection{Style of behaviour}

The number of works including affective aspects in the field of computer science is growing exponentially. Previously [24], we proposed a model to define styles of behaviour in agents to represent the decision-makers' intentions. We adopted the conflict styles proposed by Rahim and Magner [25], and redefined them to be more adequate to our context. We called them styles of behaviour and defined them as follows:

- Dominating: A dominating individual believes that he owns the key to solve the problem. He plays a very active role during the decision-making process and tries to force his opinion on other participants;

- Integrating: An integrating individual favours a collaborative style. He aims to achieve consensual decisions and greatly values his and others' opinion. He prefers to manage assiduously the entire decision-making process;

- Compromising: A compromising individual favours a collaborative style. He aims to achieve consensual decisions and values his and others' opinion. He plays a moderately active role during the decision-making process;

- Obliging: An obliging individual tends to give up on his opinion in favour of the group interests. He prefers to follow others' opinions rather than sharing his own;

- Avoiding: An avoiding individual prefers to be freed from responsibility. Fundamentally, he prefers to not be involved in the decision-making process and devalues both the process and the opinion of other participants.

In this proposal, we consider the styles of behaviour described before to formulate the satisfaction model. However, this proposal can be easily adapted to situations where aspects such as personality and conflict styles are used. In this satisfaction model, we aim to assess the decision-maker's satisfaction, so we use behaviour to understand the impact of the process in the decision-maker. The process impact will vary according to the decision-maker's intentions. For instance, let us consider a situation where the participant defined his conflict style as "Dominating". If he notices that the most of other decision-makers do not like his preferred alternative, we can associate to him emotions as distress and disappointment. On the other hand, if the participant defined his conflict style as "Obliging", he may not feel the same emotions because his main intention his not to achieve is preferred alternative but to please some other/s decision-maker/s. This is a simple example to demonstrate that the impact will vary according to how the decision-maker experiences the process. 
We define a set of situations that decision-makers experience using a GDSS and correlate them with conflict styles, using the OCC model [26]. Ortony, Clore and Collins [26] proposed a global structure of emotion types where they defined "valenced reaction to": consequences of events, actions of agents and aspects of objects. For our purpose, we only use the consequences of events. Into the consequences of events they distinguish between the consequences for other and consequences for self, what means a remarkable correlation with the classification of conflict styles proposed by Rahim and Magner [25] where they defined the conflict styles according to the concern for self and the concern for others (see Table 1).

Table 1. Styles of behaviour

\begin{tabular}{lll}
\hline Style of behaviour & Concern for self & Concern for others \\
\hline Dominating & High & Low \\
Integrating & High & High \\
Compromising & Moderate & Moderate \\
Obliging & Low & High \\
Avoiding & Low & Low \\
\hline
\end{tabular}

Table 2. Considered events and respective definition

\begin{tabular}{|c|c|c|c|}
\hline Event & $\mathrm{CO}$ & CS & Emotions \\
\hline Participant's preferred alternative was chosen by the group & $x$ & $\checkmark$ & $\begin{array}{l}\text { Joy and (check } \\
\text { rules below) }\end{array}$ \\
\hline $\begin{array}{l}\text { Participant's preferred alternative was not chosen by the } \\
\text { group }\end{array}$ & $x$ & $\checkmark$ & $\begin{array}{l}\text { Distress and } \\
\text { (check rules be- } \\
\text { low) }\end{array}$ \\
\hline Participant changed his preference to another alternative & $x$ & $\checkmark$ & Hope \\
\hline The majority prefers the participant's preferred alternative & $x$ & $\checkmark$ & Joy and hope \\
\hline $\begin{array}{l}\text { A few or none decision-maker prefers the participant's } \\
\text { preferred alternative }\end{array}$ & $x$ & $\checkmark$ & Distress and fear \\
\hline $\begin{array}{l}\text { The preferred alternative of the decision-maker/s that the } \\
\text { participant considers credible/important was chosen by the } \\
\text { group }\end{array}$ & $\checkmark$ & $x$ & $\begin{array}{l}\text { Happy-for, joy } \\
\text { and (check rules } \\
\text { below) }\end{array}$ \\
\hline $\begin{array}{l}\text { The preferred alternative of the decision-maker/s that the } \\
\text { participant considers credible/important was not chosen by } \\
\text { the group }\end{array}$ & $\checkmark$ & $x$ & $\begin{array}{l}\text { Pity, distress and } \\
\text { (check rules be- } \\
\text { low) }\end{array}$ \\
\hline $\begin{array}{l}\text { The majority prefers the same alternative as some other } \\
\text { decision-maker/s that the participant considers credi- } \\
\text { ble/important }\end{array}$ & $\checkmark$ & $x$ & $\begin{array}{l}\text { Happy-for, joy } \\
\text { and hope }\end{array}$ \\
\hline $\begin{array}{l}\text { The majority do not prefer the same alternative as some } \\
\text { other decision-maker/s that the participant considers cred- } \\
\text { ible/important }\end{array}$ & $\checkmark$ & $x$ & $\begin{array}{l}\text { Pity, distress and } \\
\text { fear }\end{array}$ \\
\hline
\end{tabular}

We have considered that the integrating and compromising styles will be affected emotionally by the "consequences for other" and "consequences for self", the obliging 
style will be affected emotionally by the "consequences for other", the dominating style will be affected by "consequences for self" and the avoiding will not be emotionally affected. The compromising style of behaviour will be affected with a half of the emotions intensities when compared with the integrating. The set of events that may occur are expressed in the Table 2. (CO is consequences for other and CS is consequences for self).

We have defined some rules to deal with hope and fear emotions (according to [26]).

If Participant experience hope and it is confirmed

Then Participant will experience satisfaction

If Participant experience hope and it is not confirmed

Then Participant will experience disappointment

If Participant experience fear and it is confirmed

Then Participant will experience fears - confirmed

If Participant experience fear and it is not confirmed

Then Participant will experience relief

\subsection{Emotional changes and mood variation}

It is clear in the literature how important is to include in the analysis of satisfaction the affective and emotional components [18, 20,21].

Due to the brilliant work proposed by Gebhard [27] where he correlates the PAD [28] and the OCC model, many works appeared using the triggered emotions in order to update the mood state (including ourselves). For this model, we propose a correlation between the events defined in Sub-section 2.3 with a set of triggered emotions for each of the situations (Table 2). We used the work proposed in [26] to define a set of emotions for each of situations and analyse the emotions triggered during the process to understand the emotional cost.

In Table 2, we presented the set of considered situations and the emotions associated to each situation. As we can see, all the situations are in some way related to the alternatives. These situations describe the scenarios the decision-makers face every time they interact with the system (GDSS). However, it is also important to define the impact of each situation. The impact of "Participant's preferred alternative was not chosen by the group", should be different if previously the participant face a situation of "A few or none decision-maker prefers the participant's preferred alternative" or a situation of "The majority prefers the participant's preferred alternative". Thus, we consider the process expectations:

$$
P_{\text {Expectations }}=N_{p} / N_{t}
$$

Where:

- $N_{p}$ is the number of decision-makers supporting the participant's preferred alternative or some other decision-maker/s that the participant considers credible/important;

- $N_{a}$ is the total number of decision-makers. 
The $P_{\text {Expectations }}$ calculated in each situation will have impact in the emotions calculated in the next interaction because every time a decision-maker faces a new situation, he will be affected by the new information plus the expectations that he created based in previous information. Next, we will describe how to process the emotions created in each situation:

Let $\mathrm{Emo}_{S}$ be a set of emotions of one situation:

$$
E m o_{S}=\left\{\left(P_{1}, A_{1}, D_{1}\right), \ldots,\left(P_{n}, A_{n}, D_{n}\right)\right\}
$$

Where:

- $n$ is the number of created emotions;

- $P_{i}, A_{i}, D_{i}$ are the values of Pleasure, Arousal and Dominance for emotion $i$ (based in [27]).

Let $E m o_{T}$ be the sum of emotions in $E m o_{S}$ :

$$
E m o_{T}=\sum_{i=1}^{n}\left(P_{i}, A_{i}, D_{i}\right)
$$

Where:

- $n$ is the number of created emotions;

- $P_{i}, A_{i}, D_{i} \in E m o_{S}$.

Let $\operatorname{Int}_{E m o_{T}}$ be the intensity of $\mathrm{Emo}_{T}$ :

$$
\operatorname{Int}_{E m o_{T}}=\frac{\sqrt{(P)^{2}+(A)^{2}+(D)^{2}}}{\sqrt{3}}
$$

Let $\operatorname{Exp}_{\text {Int }_{\text {Emo }}}$ be the $\operatorname{Int}_{\text {Emo }_{T}}$ considering $P_{\text {Expectations }}$ :

$$
\operatorname{Exp}_{\text {Int }_{E^{\prime} o_{T}}}=\operatorname{Int}_{\text {Emo }_{T}} * P_{\text {Expectations }}
$$

Let Pos $_{\text {Emotions }}$ be the sum of intensities of all positive emotions (joy, hope, happyfor, satisfaction and relief) created in each situation along the process:

$$
\operatorname{Pos}_{\text {Emotions }}=\sum_{i=1}^{n}\left(\operatorname{Exp}_{\text {Int }_{E m o} T_{i}}\right), E m o_{S} \text { is a set of positive emotions }
$$

Let Cons $_{\text {Emotions }}$ be the sum of intensities of all negative emotions (distress, fear, pity, disappointment and fears-confirmed) created in each situation along the process:

$$
\text { Cons }_{\text {Emotions }}=\sum_{i=1}^{n}\left(\operatorname{Exp}_{\text {Int }_{E m o_{T}}}\right), \text { Emo }_{S} \text { is a set of negative emotions }
$$

After calculating Pos Emotions $_{\text {and }}$ Cons $s_{\text {Emotions }}$, we compare the two intensities to understand the emotional cost. According to that, we propose the following simple rules:

If Pos $_{\text {Emotions }}=$ Cons $_{\text {Emotions }}$ 
Then Cost $=$ Neutral

If Pos $_{\text {Emotions }}>$ Cons $_{\text {Emotions }}$

Then Cost $=$ Positive

If Pos $_{\text {Emotions }}<$ Cons $_{\text {Emotions }}$

Then Cost $=$ Negative

Now, we normalize the Pos Emotions $_{\text {and }}$ ans $s_{\text {Emotions }}$, such that Pos Emotions + Cons $_{\text {Emotions }}=1$ :

$$
\begin{aligned}
\text { Norm }_{\text {Pos }_{\text {Emotions }}} & =\text { Pos }_{\text {Emotions }} /\left(\text { Pos }_{\text {Emotions }}+\text { Cons }_{\text {Emotions }}\right) \\
\text { Norm }_{\text {Cons }} \text { Emotions } & =\text { Cons }_{\text {Emotions }} /\left(\text { Pos }_{\text {Emotions }}+\text { Cons }_{\text {Emotions }}\right)
\end{aligned}
$$

The difference of intensities will then be considered as a gain or a loss (or neutral in case of no emotional cost). Let us assume this value as $D i f_{\text {Emo }}$ :

$$
\text { Cost }=\text { Norm }_{\text {Pos }_{\text {Emotions }}}-\text { Norm }_{\text {Cons }}^{\text {Emotions }}
$$

\subsection{Final satisfaction calculation}

Considering the value of participant's satisfaction concerning the alternative chosen by the group and the value of his mood (both contemplating the expectations), now we are going to join them to do our final calculation of satisfaction:

$$
\text { Satisfaction }=D_{\text {Outcomes }}+\left(1-\left|D_{\text {outcomes }}\right|\right) * \text { Cost }
$$

The interval for the result of satisfaction will be $[-1 ; 1]$. We propose an adaptation of a scale based in the work of Babin and Griffin [29] and represented in the Table 3.

Table 3. Scale of satisfaction

\begin{tabular}{ll}
\hline Designation & Interval \\
\hline Extremely Satisfied & {$[0,75 ; 1]$} \\
Much Satisfaction & {$[0,5 ; 0,75[$} \\
Satisfaction & {$[0,25 ; 0,5[$} \\
Some Satisfaction & {$[0 ; 0,25[$} \\
Some Dissatisfaction & ]$-0,25 ; 0[$ \\
Dissatisfied & ]$-0,5 ;-0,25]$ \\
Very Dissatisfied & ]$-0,75 ;-0,5]$ \\
Extremely Dissatisfied & {$[-1 ;-0,75]$} \\
\hline
\end{tabular}

\section{Conclusions and Future Work}

In this article, we proposed a whole new model which allows the automatic assessment of the participants' satisfaction in a meeting supported by a Web-based Group Decision 
Support System. We believe that the proposed model allows the attainment of a large amount of useful and valuable information. The satisfaction can be used as a metric to compare different Web-based GDSS or automatic negotiation mechanisms. In addition, satisfaction can be used as a utility function to maximize the decision-makers' satisfaction or can be used by agents to predict the decision-maker's satisfaction. To evaluate satisfaction, we considered the alternatives comparison and evaluation, the expectations, emotions, mood and the process. The values obtained in the calculus of satisfaction respect the premises that were defined in a previous work.

As future work, we intend to conduct a case study with real people, in partnership with psychologists. With that work, we also intend to make the model more assertive by the possible improvements that might result after analysing and studying the collected data.

\section{Acknowledgments}

This work was supported by COMPETE Programme (operational programme for competitiveness) within Project POCI-01-0145-FEDER-007043, by National Funds through the FCT - Fundação para a Ciência e a Tecnologia (Portuguese Foundation for Science and Technology) within the Projects UID/CEC/00319/2013, UID/EEA/00760/2013, and the João Carneiro PhD Grant with the Reference SFRH/BD/89697/2012.

\section{References}

1. Lunenburg, F.C.: Decision making in organizations. International journal of management, business and administration 15, 1-9 (2011)

2. DeSanctis, G., Gallupe, B.: Group decision support systems: a new frontier. ACM SIGMIS Database 16, 3-10 (1984)

3. DeSanctis, G., Gallupe, B.: A Foundation for the Study of Group Decision Support Systems. Management Science 33, 589-609 (1987)

4. Grudin, J.: Group Dynamics and Ubiquitous Computing. Communications of the ACM 45, 74-78 (2002)

5. Shum, S.B., Cannavacciuolo, L., De Liddo, A., Iandoli, L., Quinto, I.: Using social network analysis to support collective decision-making process. Engineering Effective Decision Support Technologies: New Models and Applications, pp. 87-103. IGI Global (2013)

6. Alonso, S., Herrera-Viedma, E., Chiclana, F., Herrera, F.: A web based consensus support system for group decision making problems and incomplete preferences. Information Sciences 180, 4477-4495 (2010)

7. Kwon, O., Yoo, K., Suh, E.: UbiDSS: a proactive intelligent decision support system as an expert system deploying ubiquitous computing technologies. Expert Systems with Applications 28, 149-161 (2005)

8. Rahwan, I., Ramchurn, S.D., Jennings, N.R., Mcburney, P., Parsons, S., Sonenberg, L.: Argumentation-based negotiation. The Knowledge Engineering Review 18, 343-375 (2003)

9. Marreiros, G., Santos, R., Ramos, C., Neves, J.: Context-Aware Emotion-Based Model for Group Decision Making. Intelligent Systems, IEEE 25, 31-39 (2010) 
10. Carneiro, J., Marreiros, G., Novais, P.: Using Satisfaction Analysis to Predict Decision Quality. International Journal of Artificial Intelligence ${ }^{\mathrm{TM}}$ 13, $45-57$ (2015)

11. Higgins, E.T.: Making a good decision: value from fit. American psychologist 55, 1217 (2000)

12. Schimmack, U., Oishi, S., Furr, R.M., Funder, D.C.: Personality and life satisfaction: A facet-level analysis. Personality and social psychology bulletin 30, 1062-1075 (2004)

13. Judge, T.A., Heller, D., Mount, M.K.: Five-factor model of personality and job satisfaction: a meta-analysis. American Psychological Association (2002)

14. Briggs, R.O., de Vreede, G.-J., Reinig, B.A.: A theory and measurement of meeting satisfaction. In: System Sciences, 2003. Proceedings of the 36th Annual Hawaii International Conference on, pp. 8 pp. IEEE (2003)

15. Tian, X., Hou, W., Yuan, K.: A study on the method of satisfaction measurement based on emotion space. In: Computer-Aided Industrial Design and Conceptual Design, 2008. CAID/CD 2008. 9th International Conference on, pp. 39-43. IEEE (2008)

16. Paul, S., Seetharaman, P., Ramamurthy, K.: User satisfaction with system, decision process, and outcome in GDSS based meeting: an experimental investigation. In: System Sciences, 2004. Proceedings of the 37 th Annual Hawaii International Conference on, pp. 37-46. IEEE (2004)

17. Beach, L.R.: Image theory: Decision making in personal and organizational contexts. Wiley Chichester (1990)

18. Liljander, V., Strandvik, T.: Emotions in service satisfaction. International Journal of Service Industry Management 8, 148-169 (1997)

19. Simon, H.A.: A behavioral model of rational choice. The quarterly journal of economics 69 , 99-118 (1955)

20. Bailey, J.E., Pearson, S.W.: Development of a tool for measuring and analyzing computer user satisfaction. Management science 29, 530-545 (1983)

21. Sherif, M., Hovland, C.I.: Social judgment: Assimilation and contrast effects in communication and attitude change. (1961)

22. Bjørn, P., Esbensen, M., Jensen, R.E., Matthiesen, S.: Does distance still matter? Revisiting the CSCW fundamentals on distributed collaboration. ACM Transactions on ComputerHuman Interaction (TOCHI) 21, 27 (2014)

23. Carneiro, J., Martinho, D., Marreiros, G., Novais, P.: A General Template to Configure Multi-Criteria Problems in Ubiquitous GDSS. International Journal of Software Engineering and Its Applications 9, 193-206 (2015)

24. Carneiro, J., Martinho, D., Marreiros, G., Novais, P.: Defining Agents' Behaviour for Negotiation Contexts. Progress in Artificial Intelligence, pp. 3-14. Springer (2015)

25. Rahim, M.A., Magner, N.R.: Confirmatory factor analysis of the styles of handling interpersonal conflict: first-order factor model and its invariance across groups. Journal of applied psychology 80, 122 (1995)

26. Ortony, A., Clore, G.L., Collins, A.: The cognitive structure of emotions. Cambridge university press (1990)

27. Gebhard, P.: ALMA: a layered model of affect. In: Proceedings of the fourth international joint conference on Autonomous agents and multiagent systems, pp. 29-36. ACM (2005)

28. Mehrabian, A.: Pleasure-arousal-dominance: A general framework for describing and measuring individual differences in temperament. Current Psychology 14, 261-292 (1996)

29. Babin, B.J., Griffin, M.: The nature of satisfaction: an updated examination and analysis. Journal of Business research 41, 127-136 (1998) 